\title{
Differential Effects of Caspase-1/Interleukin-1 $\beta-$ Converting Enzyme on Acinar Cell Necrosis and Apoptosis in Severe Acute Experimental Pancreatitis
}

\author{
Bettina Rau, Adam Paszkowski, Susanne Lillich, Katja Baumgart, Peter Möller, and \\ Hans G. Beger \\ Departments of General Surgery (BR, AP, SL, KB, HGB) and Pathology (PM), University of Ulm, Ulm, Germany
}

\begin{abstract}
SUMMARY: There is recent experimental evidence that inhibition of caspase-1/interleukin- $1 \beta$ converting enzyme (ICE) significantly ameliorates overall severity and survival in severe acute experimental pancreatitis. However, little is known about the effects of this approach on the dynamics and mechanisms of local acinar cell damage, which we aimed to investigate in the present study. Severe acute pancreatitis (SAP) was induced by retrograde infusion of $4 \%$ sodium taurocholate in rats treated with isotonic saline or a highly selective, irreversible inhibitor of ICE. After 3, 6, and 24 hours, 3 and 7 days, acinar cell death by necrosis and apoptosis, as well as intrapancreatic and systemic interleukin-1 $\beta$ (IL-1 $\beta$ ) and tumor necrosis factor- $\alpha$ (TNF- $\alpha)$ expression, was assessed. Treatment with the ICE inhibitor significantly reduced the extent of acinar cell necrosis accounting for major parenchymal destruction. In contrast, apoptosis was confined to the postacute course of the disease and was closely related to tubular complex formation, both remaining unchanged. Whereas intrapancreatic IL-1 $\beta$ mRNA expression was highly up-regulated in both treated and untreated animals, active IL-1 $\beta$ protein expression and subsequent neutrophil tissue infiltration was dramatically decreased in the ICE-inhibited group. Parallel to the onset of enhanced apoptotic acinar cell death and tubular complex formation, TNF- $\alpha$ mRNA and protein expression was up-regulated, with levels being lower in ICE inhibitor-treated rats. We conclude that activation of caspase-1/ICE plays a central role in the progression of acinar cell death by necrosis in SAP. Herein, IL-1 $\beta$-mediated neutrophil infiltration seems to be a crucial step in enhanced cellular destruction. In contrast, acinar cell apoptosis contributes to ductal transformation and is independent of this mechanism, but may be influenced by TNF- $\alpha$ (Lab Invest 2001, 81:1001-1013).
\end{abstract}

$$
T
$$
he hallmark of severe acute pancreatitis (SAP) is acinar cell injury by necrosis with subsequent recruitment of inflammatory cells in the diseased gland (Lerch and Adler, 1994). Depending on the degree of intrapancreatic damage, remote organ failure, sepsis, and, finally, patient death are frequent complications observed in the course of this disease (Isenmann et al, 1999). Whereas the initiating events leading to the development of necrosis are still poorly understood, the subsequent infiltration of different leukocyte subsets into the damaged gland are claimed to be the major source for the release of various toxic mediators, such as proteolytic enzymes (Rinderknecht, 1994), oxygen free radicals (Poch et al, 1999; Rau et al, 2000; Rinderknecht, 1994), and cytokines (Fink and Norman, 1996). In this setting, potent proinflammatory cytokines, such as tumor necrosis factor- $\alpha$ (TNF- $\alpha$ ) and interleukin-1 $\beta$ (IL-1 $\beta$ ), have been shown to mediate enhanced local tissue destruction (Denham et al, 1997) and distant organ complications (Mayer et al,

Received April 3, 2001.

This work was supported by the Deutsche Forschungsgemeinschaft, SFB/A6, to $B R$ and $P M$.

Address reprint requests to: Dr. Bettina Rau, Department of General Surgery, University of Ulm, Steinhoevelstr. 9, 89075 Ulm, Germany. E-mail:bettina.rau@medizin.uni-ulm.de
2000; Norman et al, 1997a; Norman, 1998; Ogawa, 1998).

Besides necrosis, apoptosis is another mechanism that can cause acinar cells to die (Buja et al, 1993). However, its role and its mechanisms in severe acute pancreatitis have been less well defined (lovanna, 1996). Previous reports focusing on both forms of acinar cell death have shown a relationship between the clinical severity of experimental acute pancreatitis and the incidence of necrotic or apoptotic acinar cell death. Whereas necrosis was the characteristic finding in severe experimental models, apoptosis was the predominant feature of acinar cell death in clinically mild acute pancreatitis (Gutovskaya et al, 1996; Kaiser et al, 1995). This relationship was recently confirmed in taurocholate-induced pancreatitis as well. However, beyond this observation, apoptosis was found to represent a late, postacute feature of acinar cell death in severe acute pancreatitis, whereas necrosis developed very early (Rau et al, 2001b). Although there is experimental evidence that neutrophils seem to interfere with the pathophysiological mechanisms of apoptosis, the results are still conflicting and the precise mechanisms have not been clarified (Rau et al, 2001b; Sandoval et al, 1996).

Caspase-1, formerly termed interleukin-1 $\beta$-converting enzyme (ICE), was the first-described member of the still growing family of cysteine proteases, called 
caspases (Kostura et al, 1989). One of the major functions of ICE is the proteolytic cleavage of the 31 $\mathrm{kd} \mathrm{IL-1 \beta}$ precursor into its biologically active $17 \mathrm{kd}$ form. In addition to its function in various inflammatory disorders as described in clinical and experimental studies (Dinarello, 1991), IL-1 $\beta$ has been shown to play a pivotal role among the family of proinflammatory cytokines in mediating both local and systemic complications in SAP (Denham et al, 1997; Fink and Norman, 1996). Moreover, ICE interferes with the process of apoptotic cell death as well (Kuida et al, 1995) and is known to trigger TNF- $\alpha$ and FASmediated apoptosis in various tissues (Kuida et al, 1995; Roquet et al, 1996). Recent experimental studies suggest that the activation of caspase-1/ICE is an important step in the pathophysiological process of complicated acute pancreatitis. Both the overall severity of SAP and the rate of mortality from SAP were dramatically reduced by two approaches to inhibition of ICE: the administration of a selective, irreversible inhibitor and the use of mice deficient in the ICE gene (Norman et al, 1997b). However, no data exist about the effects of ICE inhibition on the dynamics and mechanisms of acinar cell death, either from necrosis or apoptosis, in SAP. In the present study, we aimed to address this issue in an experimental model of SAP using retrograde infusion of sodium taurocholate.

\section{Results}

\section{Ascites and Intrapancreatic Edema Formation, Mortality}

Ascites developed in all animals after induction of pancreatitis and reached its maximum at 6 hours irrespective of the treatment. Parallel to ascites formation, intrapancreatic edema was observed in all animals with pancreatitis and persisted almost unchanged, constituting approximately $50 \%$ of the pancreatic weight within the first 24 hours of pancreatitis onset (Table 1). However, ascites formation was significantly reduced in ICE-I-treated rats at the 24hour and 3-day intervals, and intrapancreatic edema was less expressed at the 3-hour interval (Table 1).

None of the animals died within the first 24 hours after onset of pancreatitis. In the saline-treated (SAP-S) group, 7 of 16 rats died after 3 days. The same mortality rate was observed at the 7-day interval. In contrast, only 1 of 14 animals in the ICEinhibitor-treated (SAP-ICE-I) group had died at the same time points $(p<0.04)$ (Table 1$)$.

\section{Plasma Amylase and Lipase}

In all rats with pancreatitis, significant hyperamylasemia and -lipasemia developed during the first three days after induction of pancreatitis $(p<0.02$ 0.001 ), with maximum concentrations after 6 hours. Both enzymes had returned back to normal concentrations compared with healthy control animals at the 7-day observation point. In the SAP-ICE-I group, amylase and lipase levels remained significantly lower between the 6-hour and 24-hour intervals $p<$ 0.01-0.001).
Table 1. Ascites, Intrapancreatic Edema, and Mortality Rates in Saline and ICE-Inhibitor-Treated Rats (Mean \pm SEM)

\begin{tabular}{cccl}
\hline & SAP-S & SAP-ICE-I & \multicolumn{1}{c}{$p^{*}$} \\
\hline Ascites (ml) & & & \\
$3 \mathrm{~h}$ & $4.8 \pm 0.5$ & $4.0 \pm 0.5$ & $\mathrm{NS}$ \\
$6 \mathrm{~h}$ & $7.4 \pm 0.4$ & $8.5 \pm 0.5$ & $\mathrm{NS}$ \\
$24 \mathrm{~h}$ & ${ }^{*} 3.8 \pm 1.1$ & $* 1.3 \pm 0.8$ & $<0.05$ \\
$3 \mathrm{~d}$ & $* 4.3 \pm 1.9$ & $* 0.1 \pm 0$ & $<0.001$ \\
$7 \mathrm{~d}$ & 0 & 0 & $\mathrm{NS}$ \\
Edema $(\%)$ & & & \\
$3 \mathrm{~h}$ & $* 56 \pm 6.5$ & $* 35 \pm 0.5$ & $<0.01$ \\
$6 \mathrm{~h}$ & $52 \pm 5.3$ & $51 \pm 4.2$ & $\mathrm{NS}$ \\
$24 \mathrm{~h}$ & $53 \pm 5.1$ & $47 \pm 9.0$ & $\mathrm{NS}$ \\
$3 \mathrm{~d}$ & $33 \pm 3.8$ & $31 \pm 2.6$ & $\mathrm{NS}$ \\
$7 \mathrm{~d}$ & $19 \pm 2.8$ & $23 \pm 5.3$ & $\mathrm{NS}$ \\
Mortality & & & \\
$3 \mathrm{~d}$ & $* 43.8 \%$ & $* 7.1 \%$ & $<0.036$ \\
$7 \mathrm{~d}$ & $* 43.8 \%$ & $* 7.1 \%$ & $<0.036$ \\
\hline
\end{tabular}

SAP-S, rats with severe acute pancreatitis treated with saline; SAP-ICE-I, SAP rats treated with interleukin- $1 \beta$-converting enzyme inhibitor; NS, not significant.

\section{Hematocrit and Differential White Blood Count}

Significant hemoconcentration was observed in both treated and untreated animals after 6 hours, and was followed by a stepwise decrease until the end of the observation period at 7 days. This was paralleled by an increase in the percentage of peripheral blood neutrophils and a decrease in the percentage of lymphocytes, whereas the percentage of monocytes did not rise before the 3-day time interval (Table 2). Inhibition of ICE significantly attenuated the changes in hematocrit at 6 hours and 7 days, the early increase of neutrophils and decrease of lymphocytes within 6 hours after induction of pancreatitis, and the rise of monocytes at the 3-day interval (Table 2).

\section{Plasma IL-1 $\beta$ and TNF- $\alpha$ Concentrations}

Compared with healthy controls, systemic IL-1 $\beta$ concentrations were significantly elevated during the later course of the disease at 3 days, whereas a rise of TNF- $\alpha$ was observed within the first 6 hours and again at 3 days after onset of pancreatitis (Table 3). Administration of the ICE inhibitor prevented the increase in $\mathrm{IL}-1 \beta$ levels, which remained in the same range as found in healthy control animals throughout the whole experiment. In addition, TNF- $\alpha$ concentrations were uniformly lower within the first 3 days after induction of pancreatitis in this group and remained even below the concentrations present in healthy controls (Table 3).

\section{Histology}

Light microscopy revealed wide areas of complete structural damage by necrosis (Fig. 1) involving 53\% of the pancreatic parenchyma as early as 3 hours after induction of pancreatitis. In the further course, acinar 
Table 2. Systemic Hematocrit and Differential White Blood Count in SAP-S and SAP-ICE-I Rats and Healthy Controls (Mean \pm SEM)

\begin{tabular}{|c|c|c|c|}
\hline & SAP-S ${ }^{a}$ & SAP-ICE-I ${ }^{b}$ & $p$ \\
\hline \multicolumn{4}{|l|}{ HTC (\%) } \\
\hline $\mathrm{HC}$ & $40.4 \pm 0.7$ & $40.4 \pm 0.7$ & \\
\hline $3 \mathrm{~h}$ & $49.0 \pm 1.0$ & $48.5 \pm 1.2$ & NS \\
\hline $6 \mathrm{~h}$ & $55.0 \pm 0.9$ & $49.2 \pm 1.3$ & $<0.01$ \\
\hline $24 \mathrm{~h}$ & $38.5 \pm 1.4$ & $36.1 \pm 0.7$ & NS \\
\hline $3 d$ & $39.8 \pm 1.4$ & $37.9 \pm 0.4$ & NS \\
\hline $7 \mathrm{~d}$ & $35.8 \pm 1.2$ & $39.4 \pm 0.6$ & $<0.02$ \\
\hline \multicolumn{4}{|c|}{ Neutrophils (\%) } \\
\hline $\mathrm{HC}$ & $11.1 \pm 1.6$ & $11.1 \pm 1.6$ & \\
\hline $3 \mathrm{~h}$ & $60.8 \pm 2.0$ & $69.9 \pm 2.6$ & $<0.02$ \\
\hline $6 \mathrm{~h}$ & $80.8 \pm 2.1$ & $71.2 \pm 2.9$ & NS \\
\hline $24 \mathrm{~h}$ & $45.7 \pm 3.8$ & $50.5 \pm 4.2$ & NS \\
\hline $3 d$ & $43.4 \pm 7.7$ & $32.0 \pm 1.7$ & NS \\
\hline $7 d$ & $35.0 \pm 4.3$ & $34.0 \pm 1.7$ & NS \\
\hline \multicolumn{4}{|c|}{ Lymphocytes (\%) } \\
\hline $\mathrm{HC}$ & $81.0 \pm 1.8$ & $81.0 \pm 1.8$ & \\
\hline $3 \mathrm{~h}$ & $30.2 \pm 2.1$ & $22.7 \pm 2.8$ & $<0.05$ \\
\hline $6 \mathrm{~h}$ & $11.4 \pm 2.0$ & $20.0 \pm 2.6$ & $<0.05$ \\
\hline $24 \mathrm{~h}$ & $46.9 \pm 4.0$ & $41.7 \pm 4.4$ & NS \\
\hline $3 d$ & $36.9 \pm 7.4$ & $52.8 \pm 1.9$ & NS \\
\hline $7 \mathrm{~d}$ & $48.8 \pm 5.2$ & $52.1 \pm 2.2$ & NS \\
\hline \multicolumn{4}{|c|}{ Monocytes (\%) } \\
\hline $\mathrm{HC}$ & $4.6 \pm 0.8$ & $4.6 \pm 0.8$ & \\
\hline $3 \mathrm{~h}$ & $6.6 \pm 0.6$ & $5.7 \pm 0.4$ & NS \\
\hline $6 \mathrm{~h}$ & $7.4 \pm 0.6$ & $6.5 \pm 0.8$ & NS \\
\hline $24 \mathrm{~h}$ & $5.4 \pm 0.8$ & $4.9 \pm 0.5$ & NS \\
\hline $3 d$ & $16.9 \pm 2.0$ & $10.5 \pm 1.1$ & $<0.02$ \\
\hline $7 d$ & $10.8 \pm 1.8$ & $7.8 \pm 0.9$ & NS \\
\hline
\end{tabular}

HTC, systemic hematocrit; HC, healthy controls.

${ }^{a}$ Significant differences between SAP-S and HC: HC: $p<0.001$ (3h, 6h), $p<0.01$ (7 d); neutrophils: $p<0.001$ (3h-7d); Iymphocytes: $p<0.001$ (3h-7d); monocytes: $p<0.01(6 \mathrm{~h}, 7 \mathrm{~d}), p<0.001(3 \mathrm{~d})$.

${ }^{b}$ Significant differences between SAP-ICE-I and HC; HC: $p<0.001$ (3h-24h), $p<0.01$ (3d); neutrophils: $p<0.001$ (3h-7d); Iymphocytes: $p<0.001$ (3h-7d); monocytes: $p<0.01$ (3d), $p<0.05$ (7d).

cell necrosis involved up to $67 \%$ of the whole gland after 24 hours and remained unchanged thereafter (Fig. 2). Administration of the ICE-inhibitor did not prevent, but significantly reduced, the extent of intrapancreatic necrosis to less than $37 \%$ of the parenchyma throughout the whole experiment (Fig. 2).

In areas of pancreatic parenchyma not affected by necrosis, morphological features of ductal transformation were dominating the postacute phase of the disease. The first evidence of tubular complex formation was observed at the 3-day interval. At that time pancreatic lobules comprised structures, still resembling acini, but characterized by a decreased height of the lining epithelial layer, resulting in an increased luminal diameter with only few apical zymogen granules (Fig. 3A). This morphological change became even more apparent after 7 days, when pancreatic lobules almost exclusively contained tubular complexes with a structural phenotype equal to the pancreatic ducts, and intact acinar cells were absent (Fig. 3B). Both treated and untreated rats revealed the same morphological characteristics and dynamics of ductal transformation. Moreover, the extent of pancreatic parenchyma undergoing ductal transformation revealed no statistically significant difference between the two groups. In animals of the SAP-S group, $23.3 \pm$ $5.3 \%$ ( 3 days) and $27.2 \pm 8.1 \%$ ( 7 days) of the pancreatic parenchyma and in animals of the ICEinhibitor-treated group, $34.6 \pm 4.4 \%$ (3 days) and 39.0 $\pm 4.8 \%$ (7 days) of the pancreatic parenchyma was found to undergo ductal transformation $(p=N S)$.

\section{In Situ TUNEL Staining}

In situ terminal transferase-mediated dUTP nick end labeling (TUNEL) staining of internucleosomal DNA strand brakes was negative in all acinar cells with severe taurocholate-induced structural damage. Within the first 6 hours after induction of pancreatitis, only single acinar cells without histological evidence of damage were TUNEL-positive. At the 24-hour interval, the number of apoptotic cells increased, reached a maximum after 3 days, and decreased thereafter (Fig. 4). Apoptosis was confined to areas of pancreatic parenchyma not affected by necrosis, but revealing features of ductal transformation. In these areas TUNEL-positive cells were preferably detected in the vicinity of tubular complexes and within their epithelial 
Table 3. Systemic Tumor Necrosis Factor- $\alpha$ and Interleukin-1 $\beta$ Concentrations in SAP-S and SAP-ICE-I Rats and Healthy Controls (Mean \pm SEM)

\begin{tabular}{cccl}
\hline & SAP-S $^{a}$ & SAP-ICE-I $^{b}$ & \multicolumn{1}{c}{$p$} \\
\hline TNF- $\alpha(\mathrm{pg} / \mathrm{ml})$ & & & \\
HC & $11.8 \pm 0.4$ & $11.8 \pm 0.4$ & \\
$3 \mathrm{~h}$ & $14.3 \pm 0.7$ & $8.1 \pm 0.5$ & $<0.001$ \\
$6 \mathrm{~h}$ & $14.2 \pm 0.6$ & $9.2 \pm 0.6$ & $<0.001$ \\
$24 \mathrm{~h}$ & $12.8 \pm 0.7$ & $10.4 \pm 0.3$ & $<0.02$ \\
$3 \mathrm{~d}$ & $22.5 \pm 5.1$ & $9.9 \pm 1.0$ & $<0.001$ \\
$7 \mathrm{~d}$ & $9.9 \pm 1.4$ & $11.0 \pm 2.0$ & $\mathrm{NS}$ \\
$\mathrm{IL}-1 \beta(\mathrm{pg} / \mathrm{ml})$ & & & \\
$\mathrm{HC}$ & $92 \pm 25$ & $92 \pm 25$ & \\
$3 \mathrm{~h}$ & $104 \pm 7$ & $102 \pm 9$ & $\mathrm{NS}$ \\
$6 \mathrm{~h}$ & $125 \pm 16$ & $89 \pm 7$ & NS \\
$24 \mathrm{~h}$ & $108 \pm 7$ & $94 \pm 9$ & NS \\
$3 \mathrm{~d}$ & $358 \pm 56$ & $120 \pm 22$ & $<0.001$ \\
$7 \mathrm{~d}$ & $193 \pm 62$ & $92 \pm 7$ & NS \\
\hline
\end{tabular}

TNF- $\alpha$, tumor necrosis factor- $\alpha$; IL-1 $\beta$, interleukin- $1 \beta$.

${ }^{a}$ Significant differences between SAP-S and HC: TNF- $\alpha ; p<0.01$ (3h, 6h); IL-1 $\beta: p<0.01$ (3h).

${ }^{b}$ Significant differences between SAP-ICE-I and HC; TNF- $\alpha ; p<0.001$ (3h), $p<0.02$ (6h, 24h); IL-1 $\beta: p=$ NS.

lining cells at 3 days (Fig. 5A) and 7 days (Fig. 5B) after pancreatitis induction. There was no difference, in terms of the dynamics and number of TUNEL-positive events (Fig. 4), between SAP-S and SAP-ICE-I rats at all time intervals.

\section{Hoechst Staining}

Hoechst staining revealed enhanced occurrence of condensed chromatin in the nuclei of non-necrotic acinar cells at the 3-day (Fig. 6A) and 7-day (Fig. 6B) intervals after induction of acute pancreatitis. As observed by using the TUNEL method, positive events were localized within areas of pancreatic parenchyma characterized by ductal transformation.

\section{Electron Microscopy}

The typical ultrastructural features of apoptosis, such as nuclear shrinkage, chromatin condensation, formation of apoptotic bodies, and whorling of the rough endoplasmic reticulum (RER), were absent in acinar cells within the early course of pancreatitis. However, consistent with the results of in situ TUNEL staining, enhanced apoptosis of acinar cells was present at the 3-day (Fig. 7A) and the 7-day intervals (Fig. 7B) and was accompanied by an increased number of macrophages. The cellular source comprising the epithelial lining of the tubular complexes still showed morphological characteristics of acinar cells at the 3-day interval (Fig. 8A). After 7 days, however, increased numbers of ductlike cells with indented nuclei and sparse cytoplasmic organelles were found within the tubular complexes (Fig. 8B).

\section{Pancreatic Tissue MPO}

Along with the progression of necrosis, inflammatory cells began to invade the diseased gland 3 hours after

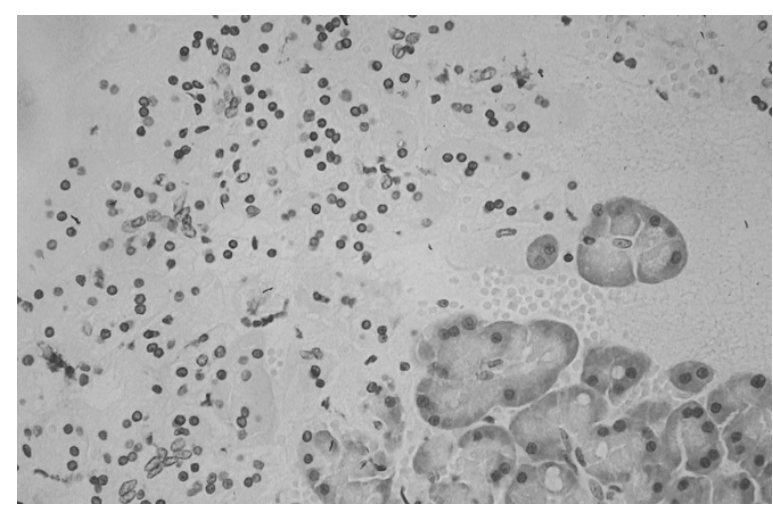

Figure 1.

Acinar cell damage by necrosis with areas of complete destruction of pancreatic parenchyma 3 hours after retrograde infusion of $4 \%$ sodium taurocholate (hematoxylin- and eosin-stained [H\&E]; $\times 400$ magnification).

the induction of pancreatitis. At that time, myeloperoxidase (MPO) levels reflected already significant neutrophil tissue infiltration compared with healthy control animals $(0.8 \pm 0.9 \mathrm{U} / \mathrm{g}$ protein, $p<0.01)$. During the following time intervals, MPO concentrations continuously increased until excessive levels of more than $2000 \mathrm{U} / \mathrm{g}$ protein were reached at the 7-day observation period in animals of the SAP-S group (Fig. 9). This was in line with the histological findings in which wide areas of complete necrosis were almost completely replaced by an extensive inflammatory infiltrate. Inhibition of ICE led to a dramatic decrease of neutrophil tissue infiltration as shown by significantly lower MPO concentrations at all time points after the 6-hour interval (Fig. 9).

\section{TNF- $\alpha$ and IL $1 \beta$ mRNA Tissue Expression}

Semiquantitative reverse transcription-polymerase chain reaction (RT-PCR) revealed highly up-regulated IL-1 $\beta$ mRNA tissue expression within the first 3 days after pancreatitis induction in the SAP-S group, whereas no relevant IL-1 $\beta$ mRNA concentrations were present in healthy control rats (Fig. 10). No detectable levels of TNF- $\alpha$ mRNA were found in healthy control animals or in untreated rats with SAP until the 24-hour interval. Parallel to the development of enhanced acinar cell apoptosis and tubular complex formation, TNF- $\alpha$ mRNA was up-regulated, revealed maximum expression at 3 days, and decreased thereafter. In the ICE-inhibitor-treated group, TNF- $\alpha$ mRNA expression showed the same dynamics as observed in untreated animals; however, up-regulation was lower at the 3and 7-day intervals (Fig. 10).

\section{TNF- $\alpha$ and IL-1 $\beta$ Protein Tissue Expression}

Western blot analysis revealed detectable levels of active IL- $1 \beta$ in the pancreas of healthy control animals. In untreated rats with pancreatitis, IL- $1 \beta$ protein expression was significantly up-regulated within the first 6 hours after induction of pancreatitis and decreased thereafter. In contrast, concentrations were markedly reduced in the ICE-I-treated group (Fig. 11). 


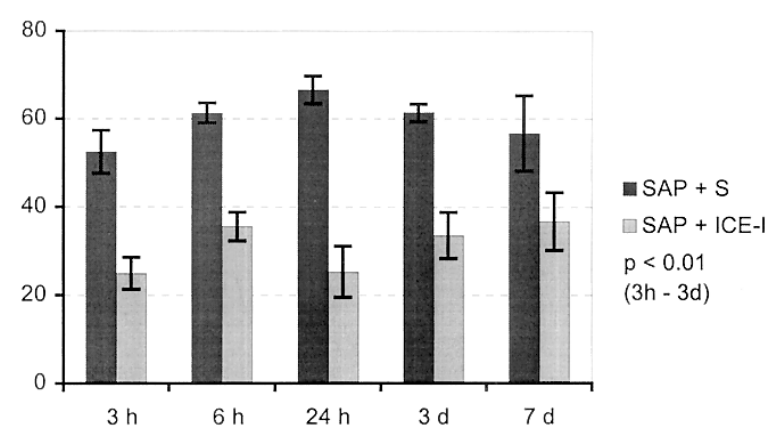

Figure 2.

Morphometric assessment of the extent of acinar cell necrosis (percentage of total pancreatic parenchyma) in saline (SAP-S) and ICE-Inhibitor (SAP-ICE-I) treated rats (mean \pm SEM). The extent of necrosis was significantly reduced between 3 hours and 3 days after induction of pancreatitis in the SAP-ICE-I group $(p<0.01)$. SAP, severe acute pancreatitis; ICE, interleukin- $1 \beta$ converting enzyme, caspase-1.

Expression of TNF- $\alpha$ was present in the pancreas of healthy control rats. In animals with pancreatitis, TNF- $\alpha$ protein concentrations remained unchanged within the first 6 hours after induction of acute pancreatitis and decreased thereafter. Parallel to the upregulation of the mRNA level, TNF- $\alpha$ concentrations slightly increased again at the 3- and 7-day observation intervals in SAP-S rats, but remained below the levels found in healthy controls. In the SAP-ICE-I group, TNF- $\alpha$ protein levels were only moderately decreased during the early time intervals and no detectable bands were present after 3 and 7 days (Fig. 11).

\section{Discussion}

In the present study, we demonstrated that ICE activation inhibits the progression of acinar cell death by necrosis. Along with this, intrapancreatic protein levels of active IL- $1 \beta$ were significantly lower during the early stages after onset of pancreatitis, and this was followed by a dramatic decrease of tissue neutrophil activation/infiltration during the later intervals. Parallel to the degree of neutrophil infiltration, systemic concentrations of $\mathrm{IL}-1 \beta$ reached maximum values during the same period and were again significantly decreased in animals treated with the ICE-inhibitor. Our results indicate that ICE-dependent activation of IL-1 $\beta$ is a local event during the early stages of acute pancreatitis and acts as an indirect mediator for promoting neutrophil activation rather than exerting direct toxic effects on acinar cells (Denham et al, 1998). Infiltrating leukocyte subsets, especially neutrophils, are the effectors for enhancing tissue destruction and the sources of ongoing systemic cytokine release, which has been extensively demonstrated in the literature (Poch et al, 1999; Rau et al, 2001b; Rinderknecht, 1994; Sandoval et al, 1996). Following their local increase, the subsequent rise of systemic cytokine concentrations significantly correlated with the overall mortality, and this underscores their pathophysiological impact on the development of overall disease severity. Beyond the generation of active
A

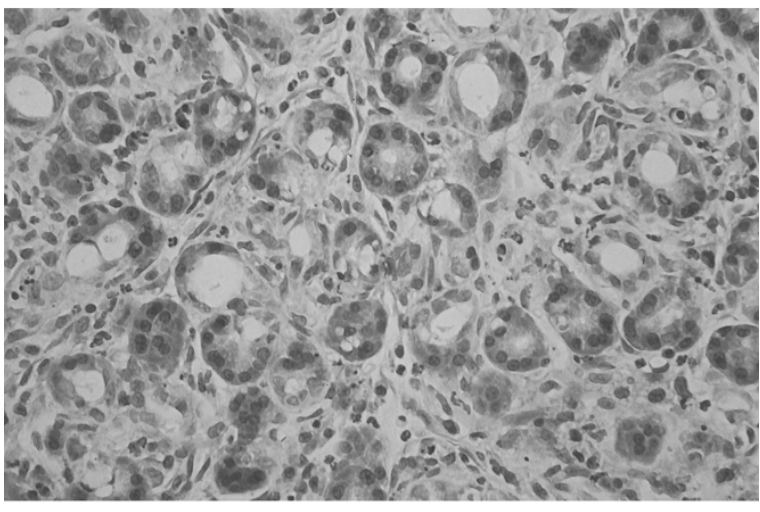

B

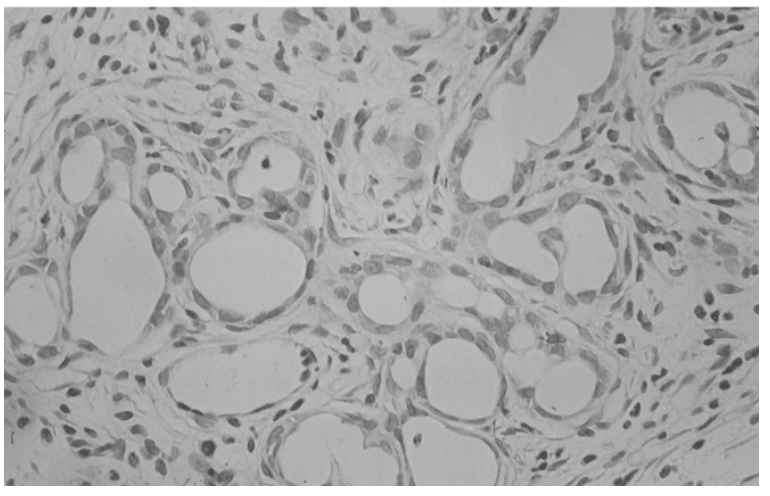

Figure 3.

A, First evidence of ductal transformation in non-necrotic areas of pancreatic parenchyma 3 days after taurocholate-induced acute pancreatitis. Tubular complexes still appear similar to acinar cells with an increased luminal diameter (H\&E; $\times 400$ magnification). B, Advanced ductal transformation in non-necrotic areas of pancreatic parenchyma 7 days after taurocholate induced acute pancreatitis. Tubular complexes appear duct like with a flat epithelial lining and a large luminal diameter (H\&E; $\times 400$ magnification).

IL-1 $\beta$, ICE-activation affects both the local and systemic release of TNF- $\alpha$ (Norman et al, 1997b), which is well known to adversely affect the course of this disease. Apart from cytokine mediated tissue damage, a direct effect of ICE on the acinar cell integrity has to be taken into account. Within the first 6 hours after induction of pancreatitis, the extent of necrosis was significantly reduced in treated animals, although MPO concentrations did not change. Because epithelial cytoskeletal microfilaments or nuclear envelope mesh components, such as actins and laminins, are other substrates that are cleaved by ICE (Thornberry and Lazebnik, 1998), direct membrane-protective effects are likely to result from the application of this inhibitor.

On the other hand, acinar cell death by apoptosis occurs during the postacute phase of the disease and is not regulated by ICE-dependent mechanisms. In an overall sense, the late onset of this form of acinar cell death, on the one hand, and the absence of any significant differences in treated and untreated animals, on the other, suggest that apoptosis is not a relevant factor in the determination of systemic severity and mortality in the model studied. Compared with 


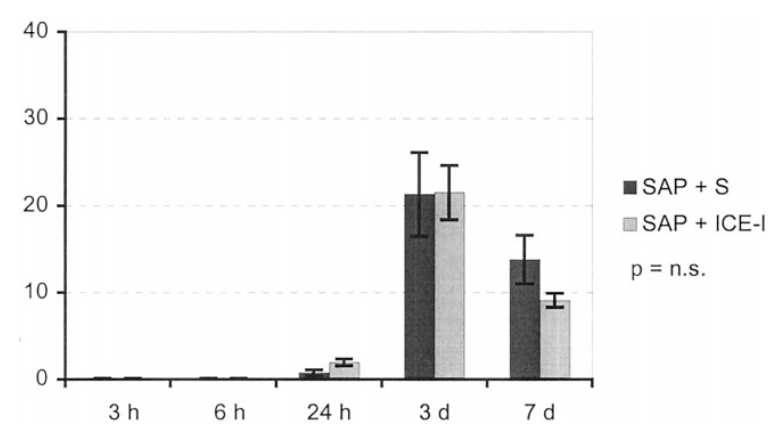

Figure 4.

Extent of acinar cell apoptosis revealed by in situ terminal transferasemediated dUTP nick end labeling (TUNEL) staining (number of apoptotic acinar cells in non-necrotic pancreatic parenchyma per microscopic high power field) in saline (SAP-S) and ICE-inhibitor (SAP-ICE-I) treated rats (mean \pm SEM). The apoptotic index was not different in both groups.

the high incidence of acinar cell death by necrosis, the amount of apoptosis in the present model of SAP was rather low. This is in agreement with previous observations that the clinical severity of acute pancreatitis is indirectly related to the degree of apoptosis (Gukovskaya et al, 1996; Kaiser et al, 1995; Sandoval et al, 1996). Because treatment with the ICE-inhibitor led to a significant reduction of overall severity and mortality, apoptosis should have increased according to this theory, but such was not the case. A more thorough morphological analysis revealed that apoptosis was exclusively confined to non-necrotic pancreatic parenchyma characterized by structural changes of ductal transformation resembling those observed in chronic pancreatitis (Bockman, 1997; lovanna, 1996), which was neither in a qualitative nor a quantitative respect different in treated and untreated animals. In these areas apoptotic events were observed in the close vicinity of, or within, the so called "tubular complexes." Recent reports focusing on the pathomorphology and origin of these complexes are in accord with our observations. Herein, apoptosis was shown to be the major cause of acinar cell loss and the development of the typical picture of pancreatic atrophy, whereas complex formation itself was the result of enhanced ductlike cell proliferation along with increased apoptosis of these cells (Reid and Walker, 1999). Proliferating ductlike cells, in turn, were even associated with the formation of new acinar cells. On the basis of these findings, the occurrence of apoptotic acinar cell death seems to reflect the remodeling capacity, after an acute attack, of the pancreatic parenchyma, which is uniformly higher in mild pancreatitis with restitutio ad integrum usually being the rule. Therefore, apoptotic acinar cell death is most likely indirect evidence of a mild course of disease, but probably no target for therapeutic interventions to decrease the overall severity and mortality of this disease.

An interesting and previously unknown phenomenon observed in the present experiment was the difference in IL-1 $\beta$ and TNF- $\alpha$ expression within the development of the disease on both the mRNA and protein levels. Although dependent on regulation by
A

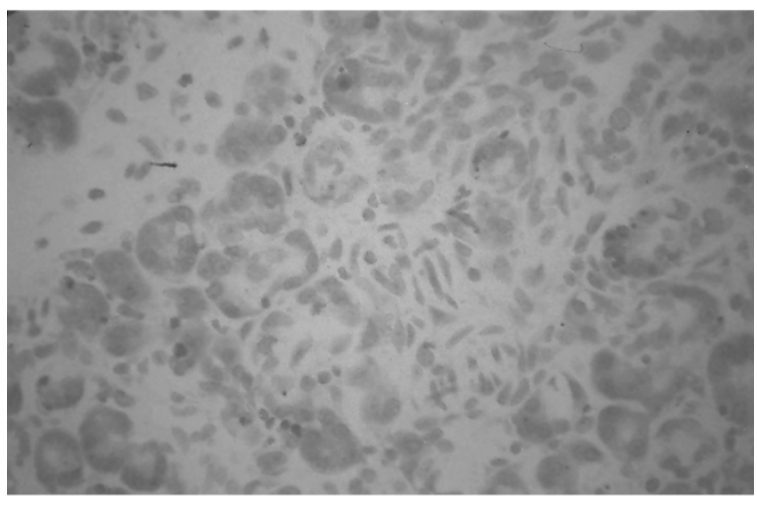

$\mathrm{B}$

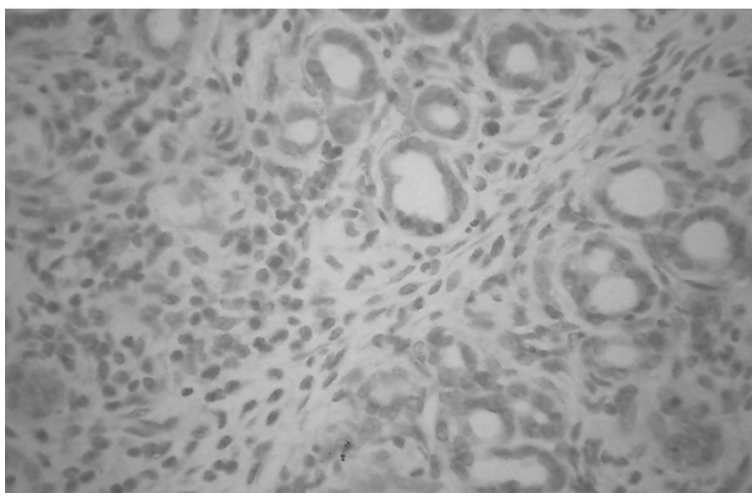

Figure 5.

Positive TUNEL staining in areas of non-necrotic pancreatic parenchyma with features of ductal transformation 3 days $(A)$ and 7 days (B) after induction of pancreatitis (Hemalaun; $\times 400$ magnification).

ICE, with similar effects on overall severity, the role of these two cytokines in the regulation of either form of acinar cell death is obviously different. The expression of active IL- $1 \beta$ and TNF- $\alpha$ protein in the pancreata of healthy control animals without any evidence of intrapancreatic leukocyte infiltration and in the absence of detectable mRNA levels strongly suggests that both cytokines are synthesized and stored within the acinar cells themselves and play a physiologic role in the process of tissue homeostasis. So far, this has only been demonstrated for TNF- $\alpha$ (Gukovskaya et al, 1997). During the early stages of acute pancreatitis, considerable amounts of intrapancreatic IL-1 $\beta$ and TNF- $\alpha$ seem to be released by acinar cells undergoing necrosis, which correlates well with the difference in the extent of necrosis found between the treated group and untreated group. This initial cytokine release is then, at least in part, responsible for triggering the inflammatory cascade including their own production in other cellular sources, such as infiltrating and circulating leukocyte subsets (De Beaux et al, 1996; McKay et al, 1996; Norman et al, 1997a).

Compared with healthy controls, IL- $1 \beta$ mRNA representing de novo cytokine synthesis was already highly up-regulated early in the course of diseased animals and correlated well with the degree of leukocyte infiltration and the progression of necrosis. In 
A

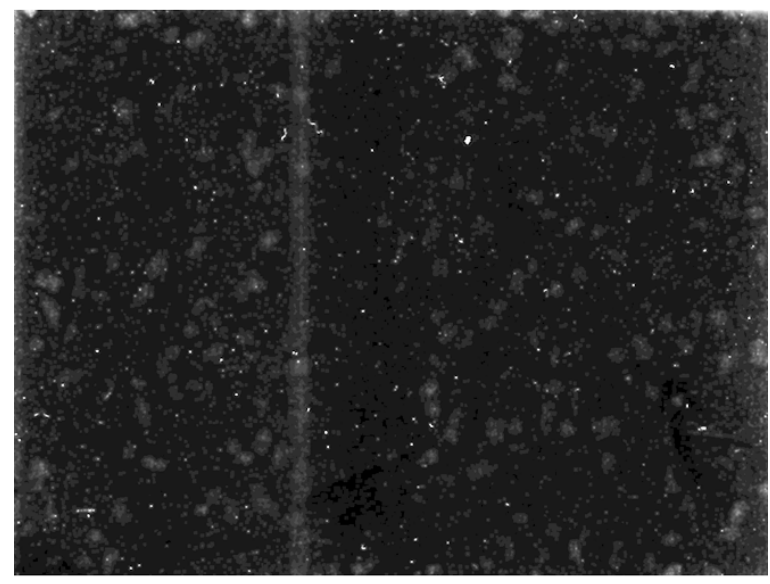

B

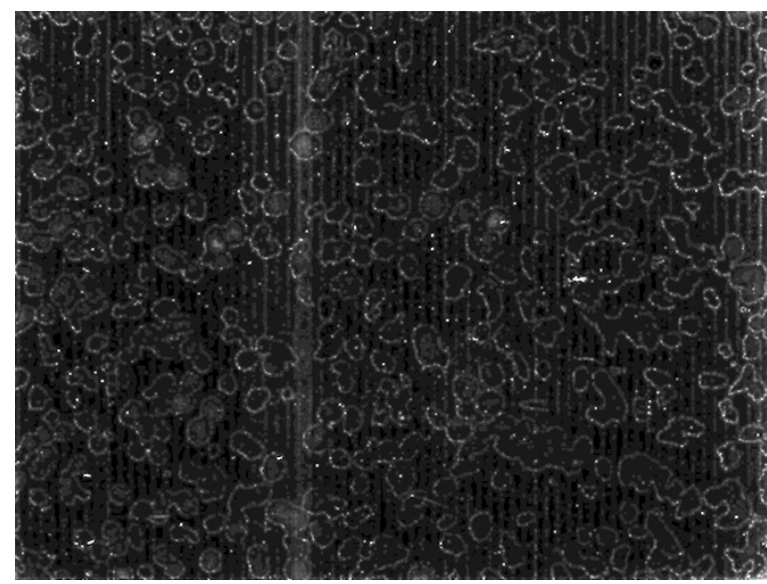

Figure 6 .

Hoechst staining in serial sections of the same animals as shown in Figure 5. Positive events were found in non-necrotic parenchyma undergoing ductal transformation 3 days $(A)$ and 7 days $(B)$ after induction of pancreatitis $(\times 200$ magnification).

contrast, TNF- $\alpha$ mRNA expression showed obvious parallels to the occurrence of tubular complex formation and apoptotic acinar cell death during the late stages of acute pancreatitis. This suggests that, in the model investigated, ICE-activated cytokines such as $\mathrm{IL}-1 \beta$, rather than TNF- $\alpha$, are responsible for mediating the progression of necrosis. It is well known that there are model-dependent differences with respect to the development of acinar cell damage/necrosis, which develops within hours in mice in the caeruleininduced model and over days in the choline-deficient ethionine-supplemented (CDE)-diet-induced model (Lerch and Adler, 1994). Independent from the model, however, intrapancreatic up-regulation of TNF- $\alpha$ mRNA occurred either simultaneously with or preceded that of IL-1 $\beta$ (Norman et al, 1997a). Because both IL-1 $\beta$ and TNF- $\alpha$ are "first order" cytokines with similar biological properties, the production of each is closely related to induction by the other, making separation often difficult. This may also explain the similar effects in reducing local pancreatic damage, distant organ failure, and mortality in several experi-
A

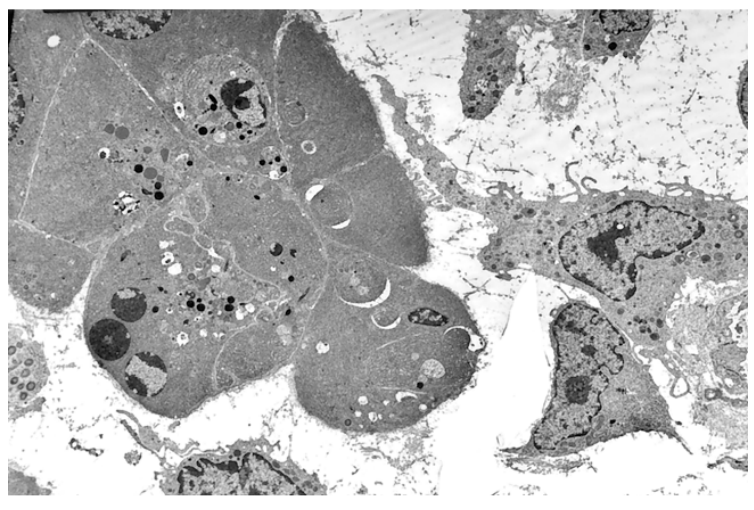

B

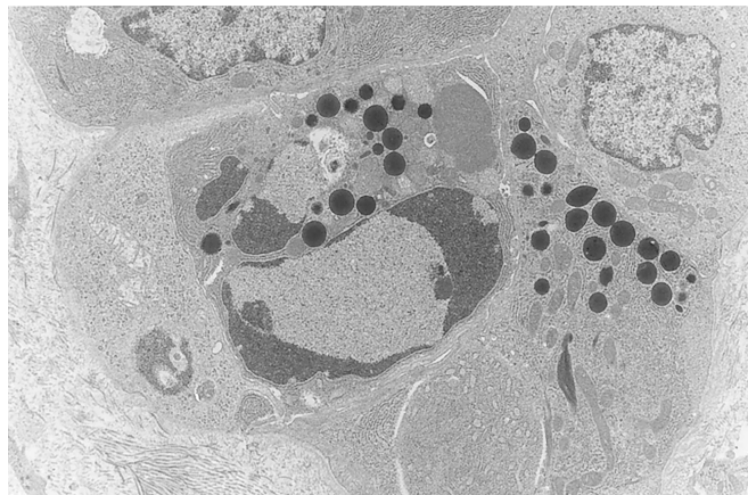

Figure 7.

A, Ultrastructural appearance of acinar cell apoptosis 3 days after induction of pancreatitis. Apoptotic acinar cells show clumped chromatin, large nucleolar remnants and whorling of endoplasmic reticulum 3 days after onset of pancreatitis. Groups of macrophages are present in the close vicinity, some of them bearing phagocytosed cellular material in the cytoplasm $(\times 1900)$. B Ultrastructural appearance of apoptotic acinar cells with the typical morphological features 7 days after induction of pancreatitis. An intraepithelial macrophage is commencing to engulf the dying acinar cell $(\times 4500)$.

mental studies by inhibiting either cytokine (Denham et al, 1997; Norman, 1998). Because no data are available about the dynamics of intrapancreatic cytokine gene or protein activation in a model of rapid onset severe pancreatitis, this is the first report so far that the role of ICE-activated cytokines seems to outweigh the deleterious effects of TNF- $\alpha$. The assessment of the systemic concentrations of IL-1 $\beta$ and TNF- $\alpha$ further supports this hypothesis. IL-1 $\beta$ concentrations reached maximum concentrations up to 300 $\mathrm{pg} / \mathrm{ml}$ at the 3rd day after onset of symptoms, whereas systemic TNF- $\alpha$ levels never exceeded 50 $\mathrm{pg} / \mathrm{ml}$ during the whole observation period.

In terms of ductal transformation and acinar cell apoptosis, the absence of any difference between treated and untreated rats indicates that ICEdependent mechanisms are not involved in the regulation of apoptotic acinar cell death in the model studied. This is in line with recent observations that do not identify ICE as the primary mediator in the pathophysiology of apoptosis (Thornberry and Lazebnik, 1998; Zeuner et al, 1999). In addition, susceptibility to apoptosis is organ-specific, and various regulatory 

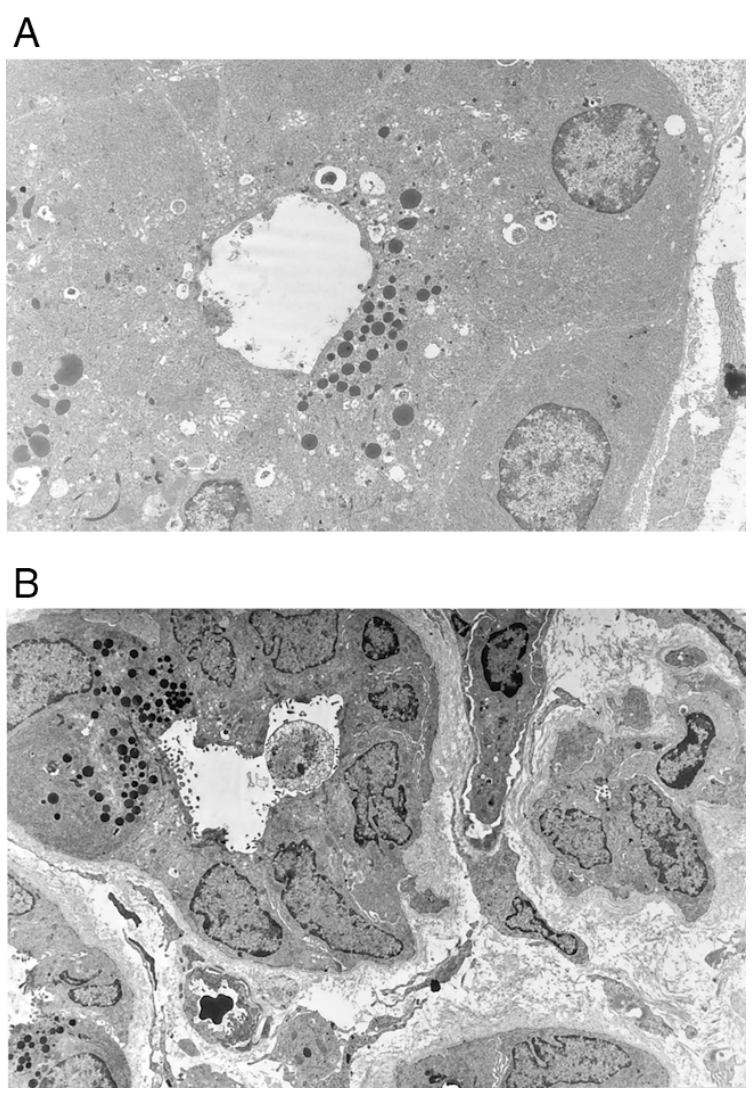

Figure 8.

A, Ultrastructural appearance of a tubular complex 3 days after induction of pancreatitis with an increased luminal diameter. The epithelial lining resembles acinar cells with some remaining zymogen granules at the apical border $(\times 3400)$. B, Ultrastructural appearance of a tubular complex 7 days after pancreatitis induction. Single epithelial lining cells still reveal features of acinar cells, however, the majority of cells are consistent with duct-like epithelium $(\times 1900)$.

pathways exist in each cellular source (lovanna, 1996; Ksontini et al, 1998; Kuida et al, 1995; Roquet et al, 1996). This becomes evident when the effects of the inhibitor used in our study are compared in two different organs and models: whereas TNF- $\alpha$ - and FAS-induced liver apoptosis was significantly decreased (Roquet et al, 1996), the same inhibitor was ineffective in modulating acinar cell apoptosis in acute pancreatitis. Although TNF- $\alpha$ is known to be involved in acinar cell apoptosis in acute pancreatitis (Gukovskaya et al, 1997), it did not seem to be the only mechanism involved in the regulation of apoptotic acinar cell death in the current study, because TNF- $\alpha$ expression in ICE-I-treated animals was reduced despite the same incidence of apoptosis. Other factors, such as expression and up-regulation of the FAS/FAS ligand system, may outweigh TNF- $\alpha$ in this respect (lovanna, 1996; Roquet et al, 1996).

Beyond the generation of active IL-1 $\beta$, ICE is also known to process the inactive precursor of interleukin-18 (IL-18) into its bioactive form (Fantuzzi and Dinarello, 1999). IL-18, formerly called interferon- $\gamma(\mathrm{IFN}-\gamma)$-inducing factor, is a novel proinflammatory $18 \mathrm{kd}$ cytokine playing an important role in the Th-1 response, primarily because of its ability to

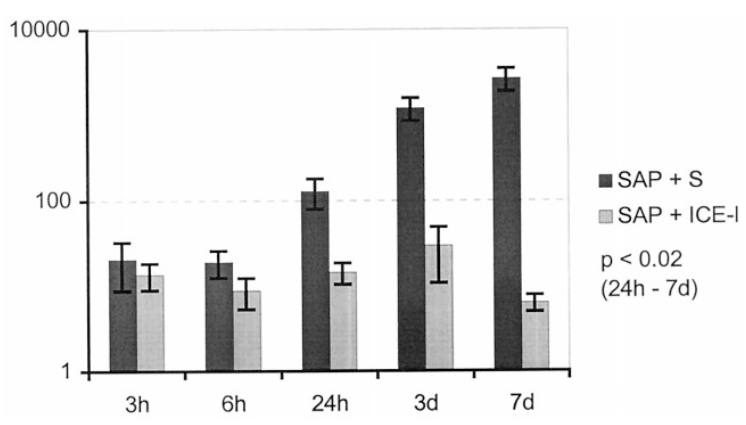

Figure 9.

Tissue myeloperoxidase (MP0) concentrations (U/g protein) in saline (SAP-S) and ICE-Inhibitor (SAP-ICE-I) treated rats (mean \pm SEM). Treatment with the ICE-inhibitor lead to a significant reduction of MPO levels from the 24-hour point to the end of the observation period $(p<0.02)$.

induce IFN- $\gamma$ production in T cells and natural killer cells (Dinarello, 1999). IL-18 and IL-1 $\beta$ share striking similarities in structure and function. In a recent study, IL-18 antagonism was highly effective in protecting mice against gram-negative endotoxemia (Netea et al, 2000). In instances of acute pancreatitis, we recently showed that, similarly to IL-1 $\beta$, serum IL-18 concentrations were significantly increased in patients with a severe course complicated by the development of pancreatic necrosis and remote organ failure (Rau et al, 2001a). The effectiveness of the inhibiting function of ICE could, therefore, also be the combined result of a decreased generation of mature IL-18 and IL-1 $\beta$, but this remains to be proven in further experimental studies.

In summary, activation of caspase-1/ICE plays a central role in the progression of acinar cell death by necrosis as well as in the determination of systemic severity and mortality in SAP. Herein, IL-1 $1 \beta$, as ICEactivated cytokine, is released and synthesized within the pancreas early in the course of the disease and seems to be an important mediator for subsequent enhanced neutrophil-induced tissue injury. In contrast, acinar cell death by apoptosis is closely related to tubular complex formation during the postacute course of the disease and does not have a significant impact on overall disease severity. Regulation of acinar cell apoptosis in acute pancreatitis is independent of ICE but may be influenced by TNF- $\alpha$. In the clinical context, inhibition of ICE represents a potential target for a new therapeutic approach in acute pancreatitis.

\section{Material and Methods}

\section{Experimental Procedures}

Animal experiments were performed in accordance with the national guidelines for the use and care of laboratory animals and approved by the local animal care and use committee of the University of Ulm. One hundred twenty male Wistar-rats $(300 \pm 2 \mathrm{~g})$ were acclimated for at least 1 week before use on a 12/12-hour light/dark cycle with free access to standard rodent chow and water. Rats were anesthetized with sevoflurane (Sevorane; Abbott, Wiesbaden, Ger- 
SAP-S

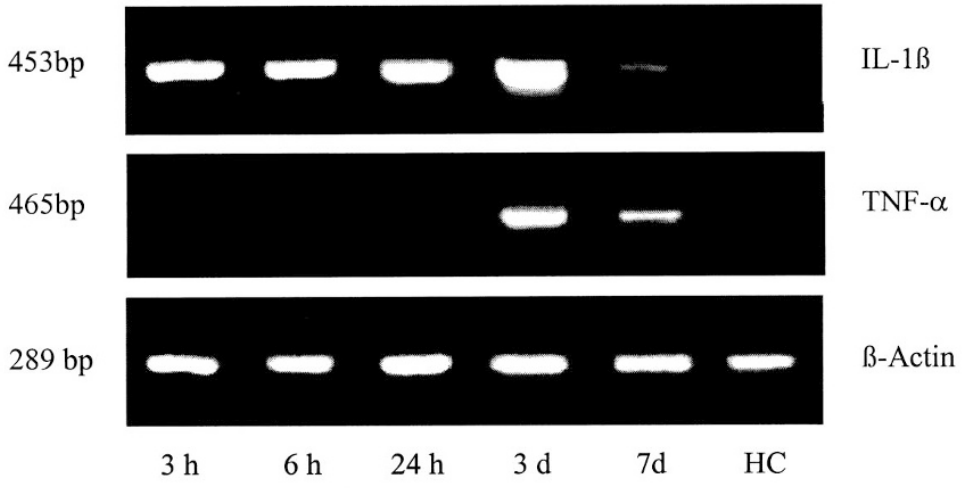

SAP-ICE-I

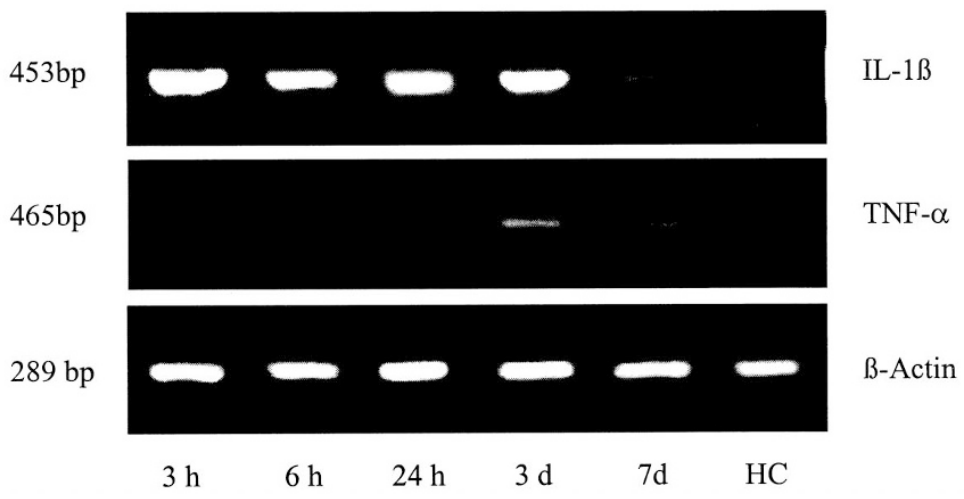

Figure 10.

Intrapancreatic mRNA expression of interleukin-1 $\beta$ (IL-1 $\beta$ ) and tumor necrosis factor- $\alpha$ (TNF- $\alpha$ ) in untreated (SAP-S) and ICE-inhibitor treated (SAP-ICE-I) rats during taurocholate induced SAP. $\beta$-actin was used as internal standard. $\mathrm{HC}$, healthy controls.

many) after receiving $0.1 \mathrm{mg} / \mathrm{kg}$ body weight buprenorphine subcutaneously (Temgesic; Grünethal, Aachen, Germany) and placed in a supine position.

Severe acute pancreatitis was induced by a standardized, pressure-controlled, retrograde infusion of $0.1 \mathrm{ml} / 100 \mathrm{~g}$ body weight of a freshly prepared $4 \%$ sodium taurocholate solution (Sigma-Aldrich Chemie, Deisenhofen, Germany) into the biliopancreatic duct as previously described (Rau et al, 2000, 2001b).

\section{Experimental Groups}

Rats were randomly assigned to treatment with either isotonic saline or a highly specific, irreversible inhibitor of ICE. After observation periods of 3 hours, 6 hours, 24 hours, 3 days, and 7 days following induction of pancreatitis, rats were exsanguinated under anesthesia by aortal puncture and intraperitoneal ascites was quantified. Total blood count and differential white blood count were deter- mined in whole blood. Plasma was analyzed for amylase, lipase, TNF- $\alpha$, and IL- $1 \beta$ concentrations. In half of the animals, the duodenal and the splenic parts of the pancreas were rapidly excised and separately processed for determination of edema formation, morphometry by light microscopic examination, in situ TUNEL staining, and electron microscopy to detect acinar cell apoptosis. In the other half of the rats, the whole pancreas was snap frozen and stored at $-80^{\circ} \mathrm{C}$ for subsequent analysis of myeloperoxidase (MPO) levels as well as extraction of total RNA and protein. Expression of TNF- $\alpha$ and IL-1 $\beta$ mRNA and protein concentrations were assessed by RT-PCR and Western-blot, respectively. Healthy animals without any previous manipulations were used to provide baseline values of the respective parameters.

Untreated Pancreatitis Group (SAP-S Group, $\mathrm{n}=$ 62). Forty-eight hours before the induction of acute pancreatitis, the rats received 12 hourly intraperitoneal injections with $1 \mathrm{ml}$ of isotonic saline. This regimen 
SAP-S

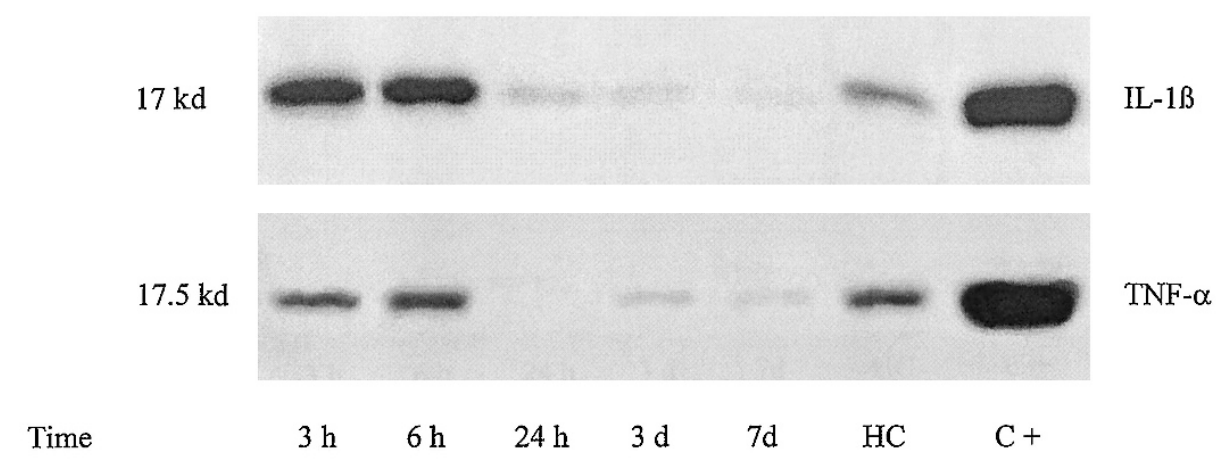

SAP-ICE-I

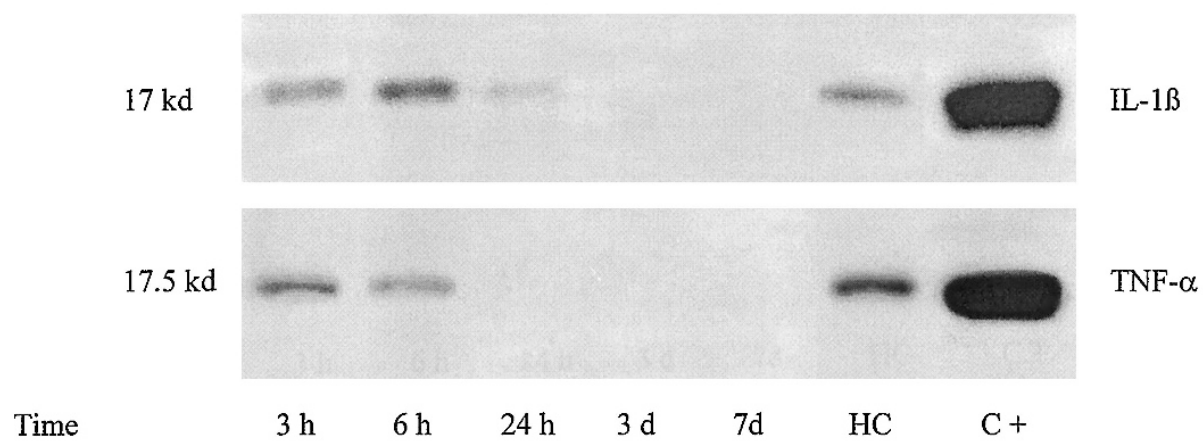

Figure 11.

Intrapancreatic protein expression of active IL-1 $\beta$ and TNF- $\alpha$ in untreated (SAP-S) and ICE-inhibitor treated (SAP-ICE-I) rats during taurocholate induced SAP. HC, healthy controls; $\mathrm{C}+, 25 \mathrm{ng}$ recombinant IL-1 $1 /$ TNNF- $\alpha$ per lane.

was continued until the rats were killed at each of the time intervals.

ICE-Inhibitor-Treated Pancreatitis Group (SAPICE-I Group, $\mathrm{n}=58$ ). Instead of saline, rats were intraperitoneally pretreated over 48 hours with 0.25 $\mathrm{mg}$ (38 $\mu$ moles) of Ac-Tyr-Val-Ala-Asp-2,6dimethylbenzoyloxymethylketone (Bachem Biochemica, Heidelberg, Germany) dissolved in $1 \mathrm{ml}$ of sterile PBS $(\mathrm{pH} \mathrm{7.4)}$ at 12 hourly intervals. This concentration of inhibitor has been shown to reduce TNF- $\alpha$ - and FAS-mediated liver apoptosis in mice (Roquet et al, 1996) and was adjusted to the body weight of the animals in the current experiment. Treatment was continued until the rats were killed at the end of each observation period.

\section{Light Microscopy}

Complete cross-sections from the duodenal and splenic parts of the pancreas were fixed in $4 \%$ phosphate-buffered formalin for 24 hours and embedded in paraffin. Two-micrometer-thick sections were either stained with hematoxylin and eosin or further processed for in situ detection of apoptosis by the TUNEL and the Hoechst methods.

\section{Electron Microscopy}

Random samples of the pancreas were fixed with $2.5 \%$ glutaraldehyde in $0.1 \mathrm{M}$ phosphate buffer $(\mathrm{pH}$ 7.4) and $1 \%$ sucrose for 24 hours. Postfixation was done with $2 \% \mathrm{OsO}_{4}$, which was followed by en bloc staining in $2 \%$ aqueous uranyl acetate and dehydration by passing through a series of graded alcohols. The tissue was then embedded in Epon 812 (Fluka Chemie, Buchs, Switzerland). Semithin sections (1 $\mu \mathrm{m})$ were stained with toluidine blue to determine the areas of interest for ultrathin sectioning. Ultrathin sections were cut on an Ultra-Cut microtome (Reichert-Jung/Leica, Bensheim, Germany), picked up on copper grids, stained with lead citrate, and analyzed with an EM 301-D 705 (Philips, Einthooven, Netherlands) electron microscope. 


\section{Assessment of Intrapancreatic Edema}

Pancreatic tissue was trimmed of fat and weighed (wet weight). Thereafter, the sample was dried at $80^{\circ} \mathrm{C}$ for 48 hours and reweighed (dry weight). The pancreatic water content was calculated as the difference between the wet and dry weights and was expressed as the percentage of the pancreatic wet weight. A rise in pancreatic water content was considered indicative of the development of pancreatic edema.

\section{Morphometric Assessment of Necrosis}

Necrosis was defined as loss of the acinar cell structure, including zymogen degranulation, loss of the basal basophilic/apical acidophilic staining of the cytoplasm, a pyknotic nucleus, and rupture of the cell membrane. At a $\times 100$ magnification, a minimum of 1000 random acinar cells per histological section were counted. Light microscopic slides were examined and graded in a blinded fashion. The amount of acinar cell necrosis was related to the total area of pancreatic parenchyma and presented as a percentage of the total.

\section{TUNEL Staining}

To detect acinar cell apoptosis, TUNEL staining of DNA fragments in situ was performed as previously described (Rau et al, 2001b). The number of TUNELpositive nuclei was counted in a blinded fashion in random high-power fields at a $\times 400$ magnification and is given as "apoptotic index" representing the number of apoptotic nuclei per high-power field.

\section{Hoechst Staining}

Nuclear staining with Hoechst dye was performed to detect chromatin condensation of apoptotic cells (Gukovskaya et al, 1996). Two-micrometer-thick deparaffinized and rehydrated formalin-fixed tissue sections were stained with $10 \mu \mathrm{g} / \mathrm{ml}$ Hoechst 33258 (Sigma-Aldrich Chemie, Deisenhofen, Germany) in PBS (pH 7.4) and mounted (Vectashield; Vector Laboratories, Burlingame, California). Stained nuclei were scored and categorized according to the condensation characteristics of the chromatin at a magnification of $\times 400$. Nuclei were considered normal if chromatin was dispersed throughout the whole nucleus. Apoptotic nuclei were identified by condensed chromatin marginated to the nuclear membrane or by nuclear fragments consisting of condensed masses of chromatin.

\section{Measurements}

Alpha-amylase and lipase activity were determined in heparinized plasma by a standard clinical method for automated analysis (DADE Behring, Liederbach, Germany). TNF- $\alpha$ and IL-1 $\beta$ were measured in EDTA plasma by using commercial enzyme-linked immunosorbent assays according to the manufacturer's instructions (R\&D Systems, Minneapolis, Minnesota).
Total blood count and differential white blood count were determined in EDTA whole blood with a ratspecific set-up on a CELLDyn counter (Abbott, Santa Clara, California) used for routine clinical analysis.

MPO was measured according to a method described by Bradley et al (1982). Tissue concentrations were related to the protein content of the pancreatic samples. The protein concentration was determined by the method of Lowry et al (1951).

\section{Semiquantitative RT-PCR}

Total RNA was extracted from pancreatic tissue using the Single-Step method of Chomczynski and Sacchi (1987). For detection of IL- $1 \beta$ and TNF- $\alpha$ by RT-PCR, $5 \mu \mathrm{g}$ of total RNA was digested with $20 \mathrm{U}$ of DNAse I (Boehringer Mannheim, Mannheim, Germany) to eliminate contamination with genomic DNA. Thereafter, $2.5 \mu \mathrm{g}$ digested total RNA underwent reverse transcription into cDNA in a total volume of $20 \mu \mathrm{l}$ in $50 \mathrm{Mm}$ Tris- $\mathrm{HCl}$ ( $\mathrm{pH} 8.3$ ), $75 \mathrm{~mm} \mathrm{KCl,} 4 \mathrm{~mm} \mathrm{MgCl}$, $10 \mathrm{~mm}$ of each dNTP, $10 \mathrm{~mm}$ DL-dithiothreitol, $40 \mathrm{U}$ human placental RNAse inhibitor, oligo(dT) primers, and 200 $U$ of SUPERSCRIPT II TM reverse transcriptase (Gibco BRL Life Technologies, Gaithersburg, Maryland) at $42^{\circ} \mathrm{C}$ for 50 minutes. Two microliters of the respective reaction mixture were further subjected to PCR. Amplification of IL-1 $\beta$ (453 bp) and TNF- $\alpha$ (465 bp) was carried out with rat-specific primer pairs (Biosource, Camarillo, California) at a concentration of $25 \mathrm{pmol}$ each in a total volume of $20 \mu \mathrm{l}$ containing $20 \mathrm{~mm}$ Tris- $\mathrm{HCl}(\mathrm{pH} 8.4), 50 \mathrm{~mm} \mathrm{KCl,} 10 \mathrm{~mm}$ of each dNTP, 1.5 $\mathrm{mm} \mathrm{MgCl}_{2}$, and $1 \mathrm{U}$ Taq DNA polymerase (Gibco BRL Life Technologies) for 35 cycles according to the manufacturer's conditions. To demonstrate the absence of genomic DNA, control experiments were performed by amplification of $2.5 \mu \mathrm{g}$ digested total RNA without reverse transcription under the same conditions. $\beta$-actin (289 bp) was used as an internal standard in each experiment to confirm equal loading of the gel. PCR products were electrophoresed on $1.5 \%$ agarose gels containing $0.1 \mu \mathrm{g} / \mathrm{ml}$ ethidium bromide and photographed under UV transillumination.

\section{Western Blot Analysis}

For Western blot analysis of IL-1 $\beta$ and TNF- $\alpha$, cytosolic protein was extracted according to the following protocol: approximately $50 \mathrm{mg}$ of pancreatic tissue was homogenized in ice-cold buffer containing $50 \mathrm{~mm}$ TRIS (pH 6.8), $150 \mathrm{~mm} \mathrm{NaCl,} 10 \mathrm{~mm}$ EDTA, 1\% Nonidet-P 40, 1 mm Sodiumorthovanadat, a proteinase inhibitor complex (all from Boehringer Mannheim), and $10 \mu \mathrm{M}$ phenylmethylsulfonyl fluoride and sonified for 10 seconds. After an incubation period of 120 minutes at $4^{\circ} \mathrm{C}$, homogenates underwent two freezethaw cycles, each followed by a centrifugation step of $16,000 \times g$ at $4^{\circ} \mathrm{C}$. Equal amounts $(50 \mu \mathrm{g})$ of the lysates were boiled in SDS-gel sample buffer for 5 minutes, separated by $15 \%$ SDS-PAGE, and transferred to nitrocellulose membranes (Amersham Life 
Sciences, Buckinghamshire, England). Nonspecific binding to the membrane was blocked by $5 \%$ nonfat dry milk in PBS, $0.1 \%$ Tween 20 (PBS-T), at room temperature for 30 minutes. The membranes were washed three times in PBS-T and incubated with a goat anti-rat polyclonal IgG antibody against IL-1 $\beta$ (1:1000) or TNF- $\alpha$ (1:1000) (Santa Cruz Biotechnology, Santa Cruz, California) at $4^{\circ} \mathrm{C}$ for 12 hours. After another three washing steps, the membranes were incubated with a secondary donkey anti-goat IgG antibody conjugated with horseradish peroxidase (1:10000; Santa Cruz Biotechnology). Following this, membranes were washed five times and developed by using the enhanced chemiluminescence system (Amersham Life Sciences) after a film exposure of 5 to 15 seconds.

\section{Statistics}

All values are presented as mean \pm standard error of the mean (SEM). Variables were tested for group differences with the Wilcoxon rank sum test. Percentages were compared by the Fisher's exact test. In all instances, $p$ values $<0.05$ at an $\alpha<0.05$ were considered significant. Statistical calculations were done with the MedCalc software package (MedCalc, Mariakerke, Belgium) (Schoonjans et al, 1995).

\section{Acknowledgements}

We thank Ms. Silke Dauser, Mr. Michael Marzinzig, Mrs. Elke Marzinzig, and Mrs. Erika Schmidt for their support and excellent technical assistance. We further thank Mr. Wolfgang Fritz and Mr. Eberhard Schmid, Department of Electron Microscopy, University of Ulm, for kindly providing tissue preparation and their expert technical support in analyzing the samples.

\section{References}

Bockman DE (1997). Morphology of the exocrine pancreas related to pancreatitis. Microsc Res Tech 37:509-519.

Bradley PP, Priebat DA, Christensen RD, and Rothstein G (1982). Measurement of cutaneous inflammation: Estimation of neutrophil content with an enzyme marker. J Invest Dermatol 78:206-209.

Buja LM, Eigenbrodt ML, and Eigenbrodt EH (1993). Apoptosis and necrosis. Basic types and mechanisms of cell death. Arch Pathol Lab Med 117:1208-1214.

Chomczynski P and Sacchi N (1987). Single-Step method of RNA isolation by acid guanidinium thiocyanate-phenolchloroform extraction. Anal Biochem 162:156-159.

De Beaux AC, Ros JA, Maingay JP, Fearon $\mathrm{KCH}$, and Carter DC (1996). Proinflammatory cytokine release by peripheral blood mononuclear cells from patients with acute pancreatitis. Br J Surg 83:1071-1075.

Denham W, Yang J, Fink G, Denham D, Carter G, Bowers V, and Norman J (1998). TNF but not IL-1 decreases pancreatic acinar cell survival without affecting exocrine function: A study in the perfused human pancreas. J Surg Res 74:3-7.

Denham W, Yang J, Fink G, Denham D, Carter G, Ward K, and Norman J (1997). Gene targeting demonstrates additive detrimental effects of interleukin-1 and tumor necrosis factor during pancreatitis. Gastroenterology 113:1741-1746.

Dinarello CA (1991). Interleukin-1 and interleukin-1 antagonism. Blood 77:1627-1652.

Dinarello CA (1999). IL-18: A Th1-inducing, proinflammatory cytokine and new member of the IL-1 family. J Allergy Clin Immunol 103:11-24.

Fantuzzi $G$ and Dinarello CA (1999). Interleukin-18 and interleukin-1 $\beta$ : Two cytokine substrates for ICE (caspase-1). Clin Immunol 19:1-11.

Fink G and Norman JG (1996). Intrapancreatic interleukin-1 $\beta$ gene expression by specific leukocyte populations during acute pancreatitis. J Surg Res 63:369-373.

Gukovskaya AS, Gukovsky I, Zaninovic V, Song M, Sandoval D, Gukovsky S, and Pandol SJ (1997). Pancreatic acinar cells produce, release, and respond to tumor necrosis factoralpha. Role in regulating cell death and pancreatitis. J Clin Invest 100:1853-1863.

Gukovskaya AS, Perkins P, Zaninovic V, Sandoval D, Rutherford R, Fitzsimmons T, Pandol SJ, and Poucell-Hatton S (1996). Mechanisms of cell death after pancreatic duct obstruction in the opossum and the rat. Gastroenterology 110:875-884.

lovanna JL (1996). Redifferentiation and apoptosis of pancreatic cells during acute pancreatitis. Int $\mathrm{J}$ Pancreatol 20: 77-84.

Isenmann R, Rau B, and Beger HG (1999). Bacterial infection and extent of necrosis are determinants of organ failure in patients with acute necrotizing pancreatitis. Br J Surg 86: 1020-1024.

Kaiser AM, Saluja AK, Sengupta A, Saluja M, and Steer ML (1995). Relationship between severity, necrosis, and apoptosis in five models of experimental acute pancreatitis. Am J Physiol 269:C1295-C1304.

Kostura MJ, Tocci MJ, Limjuco G, Chin J, Cameron P, Hillmann AG, Chartrain N, and Schmidt JA (1989). Identification of a monocyte specific pre-interleukin $1 \beta$ convertase activity. Proc Natl Acad Sci USA 86:5227-5231.

Ksontini R, Colagiovanni DB, Josephs MD, Edwards CK III, Tannahill CL, Solorzano CC, Norman J, Denham W, ClaerSalzler M, MacKay SLD, and Moldawer LL (1998). Disparate roles for TNF- $\alpha$ and FAS ligand in concanavalin A-induced hepatitis. J Immunol 160:4082-4089.

Kuida K, Lippke J, Ku G, Harding M, Livingston D, Su M, and Flavell R (1995). Altered cytokine export and apoptosis in mice deficient in interleukin 1 converting enzyme. Science 267:2000-2003.

Lerch MM and Adler G (1994). Experimental animal models of acute pancreatitis. Int J Pancreatol 15:159-170.

Lowry OH, Rosebrough NJ, Farr AL, and Randall RF (1951). Protein measurement with the folin phenol reagent. $\mathrm{J}$ Biol Chem 193:265-275.

Mayer J, Rau B, Gansauge F, and Beger HG (2000). Local and systemic cytokines in human acute pancreatitis: Clinical and pathophysiological implications. Gut 47:546-552.

McKay CJ, Gallagher G, Brooks B, Imrie CW, and Baxter JN (1996). Increased monocyte cytokine production in association with systemic complications in acute pancreatitis. $\mathrm{Br} J$ Surg 83:919-923. 
Netea MG, Fantuzzi G, Kullberg BJ, Stuyt RJ, Pulido EJ, McIntyre RC Jr, Joosten LA, Van der Meer JW, and Dinarello CA (2000). Neutralization of IL-18 reduces neutrophil tissue accumulation and protects mice against lethal Escherichia coli and Salmonella typhimurium endotoxemia. J Immunol 64:2644-2649.

Norman J (1998). The role of cytokines in the pathogenesis of acute pancreatitis. Am J Surg 175:76-83.

Norman JG, Fink GW, Denham W, Yang J, Carter G, Sexton C, Falkner J, Gower WR, and Franz MG (1997a). Tissuespecific cytokine production during experimental acute pancreatitis: A probable mechanism for distant organ dysfunction. Dig Dis Sci 42:1783-1788.

Norman J, Yang J, Fink G, Carter G, Ku G, Denham W, and Livingston $D$ (1997b). Severity and mortality of experimental pancreatitis are dependent on interleukin-1-converting enzyme. J Interferon Cytokine Res 17:113-118.

Ogawa M (1998). Acute pancreatitis and cytokines: "Second attack" by septic complications leads to organ failure. Pancreas 16:312-315.

Poch B, Gansauge F, Rau B, Wittel U, Gansauge S, Nüssler AK, Schoenberg M, and Beger HG (1999). The role of polymorphonuclear leukocytes and oxygen-derived free radicals in experimental acute pancreatitis: Mediators of local destruction and activators of inflammation. FEBS Lett 461: 268-272.

Rau B, Baumgart K, Paszkowski AS, Mayer JM, and Beger HG (In press, 2001a). Clinical relevance of caspase-1 activated cytokines in acute pancreatitis: High correlation of serum interleukin-18 with pancreatic necrosis and systemic complications. Crit Care Med.
Rau B, Paszkowski A, Esber S, Gansauge F, Möller P, and Beger HG (In press, 2001b). Anti-ICAM-1 modulates acinar cell necrosis and apoptosis in taurocholate-induced experimental acute pancreatitis. Pancreas.

Rau B, Poch B, Gansauge F, Bauer A, Nüssler AK, Nevalainen T, Schoenberg MH, and Beger HG (2000). Pathophysiological role of oxygen free radicals in acute pancreatitis: Initiating event or mediator of tissue damage? Ann Surg 231:352-360.

Reid LE and Walker NI (1999). Acinar cell apoptosis and the origin of tubular complexes in caerulein-induced pancreatitis. Int J Exp Pathol 80:205-215.

Rinderknecht H (1994). Genetic determinants of mortality in acute necrotizing pancreatitis. Int J Pancreatol 1994:16:1115.

Roquet N, Pages J-C, Molina T, Briand $\mathrm{P}$, and Joulin $\mathrm{V}$ (1996). ICE inhibitor YVADcmk is a potent therapeutic agent against in vivo liver apoptosis. Curr Biol 6:1192-1195.

Sandoval D, Gukovskaya AS, Reavey P, Gukovsky S, Sisk A, Braquet P, Pandol SJ, and Poucell-Hatton S (1996). The role of neutrophils and platelet-activating factor in mediating experimental pancreatitis. Gastroenterology 111:1081-1091.

Schoonjans F, Zalata A, Depuydt CE, and Comhaire FH (1995). MedCalc: A new computer program for medical statistics. Comput Methods Programs Biomed 48:257-262.

Thornberry NA and Lazebnik Y (1998). Caspases: Enemies within. Science 281:1312-1316.

Zeuner A, Eramo A, Peschle C, and De Maria R (1999). Caspase activation without death. Cell Death Differ 6:10751080. 